\title{
A aut onomia do paciente no processo terapêutico como valor para a saúde
}

\author{
Jussara Calmon Reis de Souza Soares ${ }^{1}$ \\ Kenneth Rochel Camargo Jr. ${ }^{2}$
}

SOARES, J.C.R.S.; CAMARGO JUNIOR, K.R. Patient autonomy in the therapeutic process as a value for health. Interface - Comunic., Saúde, Educ., v.11, n.21, p.65-78, jan/abr 2007.

This paper presents a critical review of concepts of health and disease in biomedicine, as a contribution to the establishment of new and positive health proposals. Our main point of reference is Canguilhem's epistemology, as the basis for highlighting fundamental points in the discussion about health, integrating it with the concept of patient autonomy in the therapeutic process, using an analysis method that takes an approach based on complexity. In this approach, autonomy is relative, relational and inseparable from dependence. It is also a necessary condition for health, in its broadest meaning, as the self-recovering potential of the human organism. Therefore, autonomy becomes a fundamental value to be reinstated and defended in medical practice, as well as in the social and human sciences' field. A discussion of the implications of the concept of autonomy is presented, if only as a harbinger of a future state, as a precondition for health, citizenship and for life itself.

KEY WORDS: physician-patient relation. patient autonomy. health. Canguilhem. complexity.

No presente artigo analisam-se as críticas à concepção reducionista de saúde e doença da biomedicina, buscando contribuir para um repensar sobre saúde em uma vertente de proposições positivas. Remetemo-nos, sobretudo, à epistemologia de Canguilhem, para destacar pontos fundamentais na discussão sobre saúde, integrando-a a uma nova leitura do conceito de autonomia do paciente no processo terapêutico. O método de análise seguiu a perspectiva do pensamento complexo. Nesta perspectiva, a autonomia caracteriza-se como relativa e relacional, inseparável da dependência. É também condição necessária para a saúde, compreendida em seu sentido mais amplo, como potência auto-recuperadora do organismo humano. Assim, autonomia passa a ser um valor fundamental a ser resgatado e defendido tanto na clínica, quanto no campo das ciências humanas e sociais em saúde. Discutem-se implicações do resgate da autonomia, ainda que como um vir-a-ser, como precondição para a saúde e a cidadania, para a própria vida.

PALAVRAS-CHAVE: relação médico-paciente. autonomia do paciente. saúde. Canguilhem. complexidade.

1 Professora, departamento de Saúde e Sociedade, Instituto de Saúde da Comunidade, Universidade Federal Fluminense (UFF), Niterói, RJ.<jucalmon@vm.uff.br>

${ }^{2}$ Professor, departamento de Planejamento, Política e Administração em Saúde, Instituto de Medicina Social, Universidade Estadual do Rio de Janeiro (UERJ). <kenneth@uerj.br>

${ }^{1}$ Rua Pacheco Leão, 174, bloco B, apto. 404

Jardim Botânico - Rio de Janeiro, RJ

22.460-030 


\section{Introdução}

Entre as contribuições fundamentais das ciências humanas e sociais ao campo da saúde inclui-se a crítica à hegemonia, ainda incontestável, do paradigma biológico e naturalista da chamada biomedicina ou medicina ocidental contemporânea. Além de todas as críticas que vêm sendo feitas em relação à dinâmica do processo de institucionalização e socialização da medicina, estudos indicam a necessidade de reflexões relacionadas às próprias concepções de saúde e doença.

Em 1999, por exemplo, um número da revista Physis foi inteiramente dedicado ao tema "os sentidos da saúde". Em sua apresentação, Birman (1999) reconhece que não apenas estão se produzindo sentidos novos para a palavra saúde, mas também se ordenam práticas outras para o seu engendramento e sua produção. Nos recentes seminários realizados na Universidade Estadual do Rio de Janeiro (UERJ) sobre integralidade nas ações de saúde, temas como percepções sobre doença, saúde e cura, relação médicopaciente, cuidado e necessidades de saúde da população estiveram muito presentes, como nos artigos de Luz, Pinheiro e Acioli, por exemplo (Pinheiro \& Mattos, 2001). Porém, Coelho \& Almeida Filho (2002) continuaram a apontar a dificuldade, do ponto de vista epistemológico, de conceituar saúde: "A carência de estudos sobre o conceito de saúde propriamente definido parece indicar uma dificuldade do paradigma científico dominante nos mais diversos campos científicos de abordar a saúde positivamente" (p.316). Portanto, refletir sobre conceitos como saúde, doença, vida, autonomia continua a ser fundamental em nosso campo, embora - ou talvez porque - na biomedicina ainda seja central a ciência médica, dentro de uma concepção de neutralidade e objetividade que negligencia as dimensões socioculturais presentes também no processo terapêutico.

Com este deslocamento da subjetividade para a objetividade, do respeito aos valores para o estabelecimento de regras e normas "neutras", ocorre um afastamento crescente entre médicos e pacientes, e destes em relação ao seu corpo. Diminui, assim, a capacidade de ação dos pacientes enquanto sujeitos no processo saúde/doença. Desse modo, a biomedicina vem levando ao distanciamento e à objetivação dos pacientes, à deterioração da relação médico-paciente e à perda do papel milenar terapêutico da medicina - como arte de curar - em proveito da diagnose e da ciência das doenças (Luz, 1996). Clavreul (1983) chegou a afirmar que, especialmente no contexto hospitalar, a relação médico-paciente deu lugar à relação entre instituição médica e doença, já que as subjetividades de médicos e pacientes foram excluídas. Porém, importa-nos, sobretudo, neste artigo, analisar a concepção reducionista de saúde e doença da biomedicina, analisar críticas que vêm sendo construídas e trazer contribuições para um repensar sobre saúde na vertente de proposições positivas.

Enfocamos, em especial, a epistemologia de Georges Canguilhem, para esse repensar sobre saúde e doença. De fato, este autor nos parece fundamental para a mudança que vemos como absolutamente necessária a fim de que a política do setor possa se direcionar no sentido da saúde - e não mais da doença -, como tem ocorrido ao longo da história da medicina moderna. 


\section{O aporte de Georges Canguilhem}

Por ser já um "clássico", O normal e o patológico, de Canguilhem (1995), vem sendo revisitado por muitos outros autores, além de ser referência obrigatória em diversas análises no campo da saúde. No Brasil, as reflexões feitas por Coelho \& Almeida Filho em 1999 e 2002 são um exemplo, mas nos permitimos focalizar aqui alguns pontos discutidos mais detalhadamente em Soares (2000), pois trazem importantes subsídios ao tema em questão. Toda a construção epistemológica sobre a vida gira em torno do conceito de norma, fazendo com que vida e norma se tornem um binômio indissociável (Blanc, 1998). Sua démarche permite uma inversão inter essante de uma cisão fundamental dentro de uma epistemologia positivista: para esta, o conhecimento se dá sobre um "real absoluto", e não há lugar para discussão de valores. Para Canguilhem, o conhecimento pode ser relativizado, mas há um valor fundamental, ontológico, na própria vida.

No primeiro ensaio de O normal e o patológico, o autor procura definir as condições de possibilidade de uma individualidade biológica, a partir da experiência da doença. Analisa criticamente a teoria médica e a biologia, posiciona-se contra o dogma positivista da doença e afirma a distinção qualitativa entre saúde e doença, entre normal e patológico. O organismo é considerado uma totalidade, e a doença é vista como a expressão de um novo comportamento global do organismo, não apenas como uma parte afetada. A doença é uma experiência vivida por uma individualidade, é criação de uma nova norma. Toda doença se refere a um doente que busca lhe dar um sentido. Daí a importância da perspectiva do doente no pensamento de Canguilhem (1995, p.96):

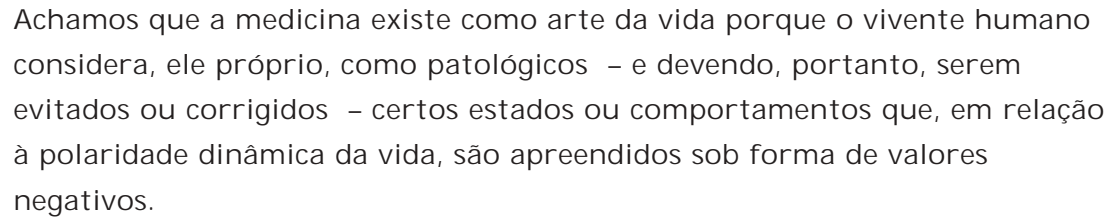

A normatividade é, portanto, o conceito-chave que permite precisar a distinção entre o normal e o patológico. Autores como Blanc (1998) vêem, nessa compreensão da normatividade como potência da vida para criar novas normas, uma aproximação com a posição de Nietzsche, para quem a vida, nela mesma, é criação de valor. Vieira (2000) também considera os conceitos nietzscheanos de vontade de poder e de eterno retorno expressão mesma da "grande saúde". É ainda com base nessa potência auto-recuperadora do organismo vivo que podemos fazer uma aproximação de Canguilhem com o conceito de autonomia em Morin (1994, 1996).

Outro ponto fundamental em Canguilhem é sua contraposição ao discurso da cientificidade da Medicina, quando afirma que é a normatividade - e não a ciência - que determina a diferença entre o normal e o patológico; deste modo, o autor não apenas remete à questão da autonomia do indivíduo doente, mas também distingue medicina de ciência. A citação a seguir é bastante ilustrativa de seu pensamento: 
Ora, a clínica não é uma ciência e jamais o será, mesmo que utilize meios cuja eficácia seja cada vez mais garantida cientificamente. A clínica é inseparável da terapêutica, e a terapêutica é uma técnica de instauração ou de restauração no normal, cujo fim escapa à jurisdição do saber objetivo, pois é a satisfação subjetiva de saber que uma norma está instaurada. Não se ditam normas à vida, cientificamente. Mas a vida é essa atividade polarizada de conflito com o meio, e que se sente ou não normal, conforme se sinta ou não em posição normativa. (Canguilhem, 1995, p.185-6, grifos no original)

O autor reclama, deste modo, um campo específico da normalidade e da patologia que escape ao domínio da ciência ao considerá-las valores, não aceitando, portanto, pressupostos da biomedicina, que se quer científica, objetiva e neutra. A crítica à visão fragmentada da biomedicina também é feita na afirmação em que conclui que:"(...) a doença de um ser vivo não se situa em determinadas partes do organismo" (p.183).

Esta concepção reforça nossa crítica ao modo de utilização dos medicamentos alopáticos na medicina, cada vez mais desenvolvidos para atuarem em partes específicas do organismo, com a perspectiva de cura das doenças, empobrecendo o potencial da terapêutica, que deveria ir muito além de uma ação pontual para solucionar um problema. A farmacoterapêutica, como definida atualmente, não tem por objetivo atuar sobre o doente, o ser vivo, mas sobre a doença entendida dentro da concepção criticada por este autor. Se tomamos o conceito de cura de Canguilhem - "curar é criar para si novas normas de vida" (p.188) podemos observar que a lógica da farmacoterapêutica científica utilizada pela biomedicina não se faz no sentido de garantir uma maior normatividade individual. Isto pode levar a uma inversão importante: o ser humano, que deveria ser o alvo da terapêutica, passa a ser mero instrumento ou intermediário da ação da droga sobre as doenças.

Ao enfatizar os conceitos de normal e patológico como valores, Canguilhem critica, ainda, o princípio de patologia dominante na biomedicina, “(...) segundo o qual o estado mórbido no ser vivo nada mais seria que uma simples variação quantitativa dos fenômenos fisiológicos que definem o estado normal da função correspondente" (p.187). Para ele, o estado patológico é um estado normal na medida em que exprime uma relação com a normatividade da vida, sendo, porém, um estado qualitativamente (e não quantitativamente, vale a pena enfatizar) diverso do normal fisiológico, o qual tem normas diferentes. Assim, a patologia não é ausência de norma, mas o estabelecimento de uma outra norma e uma restrição da normatividade.

Não há fatos normais ou patológicos em si. Norma normal é a que exprime a estabilidade, a fecundidade e a variabilidade da vida em grau equivalente ou superior a uma outra norma existente antes. É, portanto, relativa, podendo ser estabelecida por comparação, e não pode ser absolutizada, como tende a ocorrer na biomedicina. Assim,“(...) a anomalia pode transformar-se em doença mas não é, por si mesma, doença" (p.109). Anomalias e mutações apenas comprovam a diversidade da vida, suas 
múltiplas possibilidades. Mas na biomedicina, elas são muitas vezes consideradas doenças a serem suprimidas diminuindo-se, assim, a diversidade, a diferença, a heterogeneidade.

Homem normal é o homem normativo, i.e., aquele capaz de romper as normas e instituir novas normas, um homem autônomo, diríamos. Em resumo, são estas as principais contribuições do autor: além da própria conceituação de saúde, os conceitos de normal e patológico como valores, o reconhecimento da dificuldade da determinação médica do que seja normal e do que seja saúde, a valorização da perspectiva dos doentes nesse processo e da sua singularidade.

A adoção e a defesa da perspectiva vitalista de Georges Canguilhem ajudamnos a pensar em estratégias que levem ao uso crítico, ativo, consciente e responsável das diversas alternativas presentes no mundo contemporâneo, sem cair no consumismo acrítico seja de informações, de saberes ou de tecnologias. Buscamos aqui uma releitura da vis medicatrix naturae para o século XXI, o que certamente desemboca na questão da educação e da ética em um plano mais geral, em uma reflexão profunda sobre conceitos e propostas como medicina racional, medicina baseada em evidências, uso racional de medicamentos, eficácia, entre tantos outros que fazem parte do cotidiano dos profissionais do setor saúde. Faz-se necessário, também, um exame crítico de suposições implícitas, quase míticas, como o da onipotência da Medicina, o da medicina como sinônimo de saúde, o da saúde como consumo de produtos e serviços ligados à tecnologia médica. É ainda, neste contexto, que vemos a necessidade do resgate da noção de autonomia, da defesa da autonomia como valor na saúde pensada na perspectiva da complexidade.

\section{Conceitos de saúde em xeque}

Berlinguer (1988) já havia feito a crítica da biomedicina, por sua definição e avaliação da saúde como saúde instrumental, baseada em critérios de produtividade ou de adaptação. Outros autores, como Foucault e Swaan, também devem ser lembrados aqui, por suas análises de tais estratégias de intervenção.

Caponi (1997), baseando-se em Canguilhem, traz contribuições inter essantes em sua crítica às definições de saúde da Organização Mundial de Saúde (OMS) e da VIII Conferência Nacional de Saúde (CNS). A definição de saúde como "um completo estado de bem-estar físico, mental e social, e não apenas a ausência de doença", mostra a autora, pode legitimar estratégias de controle e de exclusão de todos aqueles considerados indesejados ou perigosos, ao não problematizar os conceitos aí presentes. A definição da OMS não reconhece, tampouco, que os infortúnios e as doenças fazem parte de nossa existência, e não podem ser pensados em termos de crimes ou castigos, como bem analisaram Nietzsche e Canguilhem. Falar de saúde implica falar também de dor ou prazer, reconhecer um "corpo subjetivo", como o faz Canguilhem. Daí este autor considerar que um verdadeiro médico é um exegeta, aquele que pode auxiliar o doente em sua busca de sentido para o conjunto de sintomas que ele está vivenciando e que não consegue sozinho decifrar.

Em relação ao chamado conceito "ampliado" de saúde, definido na VIII CNS 
e incluído na Constituição Federal em vigor, Caponi (1997) também apresenta uma crítica bastante interessante. Reconhece nele o mérito de enfocar a relação estreita entre saúde e sociedade, mas critica a redução a uma dimensão única determinante e absoluta no processo saúde/ doença. Perde-se qualquer referência a uma especificidade biológica ou psíquica da doença, exclui-se qualquer referência a uma dimensão vital, um reducionismo que Canguilhem não faz. Além disso, assim como a definição da OMS, o conceito ampliado da VIII CNS também pode levar à visão de que todos os âmbitos da existência humana possam ser considerados medicalizáveis.

Já Canguilhem pensa a saúde em termos de margem de segurança e tem os erros como ponto de partida. Ele supera a conceituação de saúde como o equilíbrio entre o organismo e o meio, ao afirmar que saúde implica a capacidade de instituir novas normas, uma capacidade criativa. Mas, além de ter a capacidade de auto-cuidado como um elemento central, o conceito de saúde em Canguilhem também deve contemplar, de modo privilegiado, os determinantes sociais, uma vez que o autor considera tanto os valores biológicos como os sociais, ao se referir à capacidade de tolerância para enfrentar as dificuldades.

A nosso ver, a saúde como a capacidade de romper normas e instituir novas normas é um conceito que enfatiza a diversidade, a multiplicidade, a capacidade criativa dos seres vivos, e que deveria estar sendo cada vez mais debatido pela biomedicina em busca de novos caminhos. Mas o que podemos observar é a tendência a homogeneizar, reduzindo ou suprimindo as ambivalências, os múltiplos significados das doenças, dos medicamentos, da vida, enfim. A biomedicina contemporânea não fornece instrumentos para que esse conceito de um sujeito criador de normas possa ser trabalhado. Muito pelo contrário, ela se volta cada vez mais para a doença, ou mais precisamente, para órgãos ou fragmentos com alguma sintomatologia. Como pensar em sujeitos autônomos, quando nem como pessoas esses doentes são considerados?

Jonas (1994) discute como a crescente regulação do social vem levando à perda da autonomia individual, reforçando as análises feitas por Caponi (1997), Foucault (1976, 1980), Swaan (1988), entre outros autores. Outra difícil questão abordada por Jonas é a da oposição entre manipulação tecnológica e manipulação simbólica do indivíduo:

Deveremos induzir atitudes de aprendizagem em crianças de escola através da administração maciça de drogas, ignorando o apelo à motivação autónoma? Deveremos dominar a agressividade através da neutralização electronica de zonas cerebrais? (...). (Jonas, 1994, p.53)

Assim, há uma tensão ética constantemente presente na prática médica, que vem do conflito entre os princípios da autonomia e da beneficência, da diferença entre o respeito pela liberdade e a preocupação com aquilo que mais convém às pessoas, o que remete também à questão de quem pode e deve tomar as decisões. 


\section{Novos rumos para a biomedicina}

Algumas propostas alternativas vêm emergindo mais recentemente, enfatizando a necessidade de se resgatarem valores como democracia, ética, capacidade crítica e autonomia na medicina, valores que defendemos também como fundamentais para a superação da crise de uma forma construtiva, expansiva. A medicina contemporânea deveria passar, então, a privilegiar sentimentos e valores dos pacientes, de seus familiares e dos profissionais de saúde, todos considerados envolvidos na arte de curar, e a estimular a reflexão em conjunto para as tomadas de decisões necessárias, ou seja, a democratização da relação médico-paciente, resgatando, enfim, sua humanização.

No que se refere particularmente aos modelos de decisão médica, já são inúmeros os estudos realizados (embora, no Brasil, este tema ainda possa ser considerado incipiente) com propostas de democratização das relações entre profissionais e pacientes, de valorização da autonomia do paciente em relação à escolha da terapêutica e dos procedimentos a serem seguidos, de modelos em que pacientes e médicos são vistos como co-responsáveis nesse processo. Tais propostas têm como base estudos empíricos que mostraram a associação entre um maior apoio à autonomia do paciente e melhores resultados, por exemplo, em tratamentos por abuso de drogas, redução de peso e adesão aos tratamentos. Apenas a título de ilustração, podem ser citados, nos Estados Unidos da América, Quill (1983), Brody (1985), Quill \& Suchman (1993), Quill \& Brody (1996) ou Laine \& Davidoff (1996), como autores que vêm investigando essa questão. Quill \& Brody (1996) propõem, por exemplo, o Modelo de Autonomia Intensificada, centrado na relação médico-paciente e baseado na competência e no diálogo, em que o conhecimento e a experiência são compartilhados entre pacientes e médicos, em que ambos colaboram na decisão: o médico serve como guia ativo no processo, está pessoalmente envolvido com o resultado e ambos têm responsabilidade conjunta em relação às conseqüências de suas decisões. Porém, embora válidos, a nosso ver, tais modelos se valem, de modo geral, de um conceito de autonomia bastante limitado, restrito ao interior da relação médico-paciente, sem questionar as relações de poder/saber estabelecidas, sem refletir sobre os pressupostos fundamentais dessa racionalidade médica e, assim, sem rupturas ou propostas de transformação dessas relações sociais ou da prática médica hegemônica.

Em sua crítica às políticas sociais de saúde, que exercem controles externos sobre as doenças às custas da perda de autonomia e de autocontrole dos indivíduos, das comunidades e das populações sobre os condicionantes vitais de suas próprias doenças, Dâmaso (1992) propõe uma terapêutica que seja baseada na potência auto-recuperadora do organismo humano vivo, que se oponha ao condicionamento, físico e mental, a medicamentos e demais tecnologias do complexo médico-industrial, consultas, exames, programas e sistemas de saúde. Para o autor, toda política de saúde deve ser política educacional: “'Educação para a vida', eis aí o projeto da política sanitária mais radical e coerente com o desejo humano de autonomia" (p.222). Este é mais um autor que evidencia a necessidade urgente da discussão da autonomia para a superação da crise da biomedicina, no sentido de tornar-se 
uma medicina mais humana, vitalista, que considere a complexidade, a riqueza e a potencialidade dos seres humanos. Mas, também, uma medicina que reconheça seus próprios limites e possibilidades em relação ao objetivo maior de contribuir para a saúde das populações.

Além disso, porém, defendemos que a prática da medicina deve estar voltada, cada vez mais, para a questão do "cuidado" das pessoas. A ciência e a tecnologia devem ser apenas meios, instrumentos facilitadores do fim das medicinas - sejam elas quais forem - que é cuidar dos seres humanos, contribuindo, assim, para que tenhamos saúde e as melhores condições possíveis de qualidade de vida. É este cuidado com os seres humanos que deveria ser resgatado pela biomedicina, e que as concepções vigentes de autonomia do paciente também parecem negligenciar. É por meio desse cuidado que a autonomia pode se construir, a começar pelo reconhecimento e aceitação das inúmeras redes de dependência que constituem a existência humana. Autonomia implica, também, uma enorme responsabilidade consigo e com os outros. Portanto, ser autônomo não é ser independente, não é ser egoísta, nem individualista, como parece ser uma tendência freqüente na concepção em que vem sendo tradicionalmente trabalhada a autonomia do paciente.

A partir de diversos campos de saber, podemos tecer uma rede de complexidade para uma melhor compreensão das questões envolvidas na autonomia do paciente e o processo terapêutico. Na produção desta rede (construída em Soares, 2000), recorremos a autores que trabalham em uma perspectiva inter ou transdisciplinar, buscando integrar o macro e o micro, o geral e o particular, as inter-relações e inter dependências presentes nos processos humanos, autores que vêem o todo não como a completude, mas como um todo relacional, multidimensional, processual e dinâmico, complexo, enfim. Ao procedermos assim, em uma releitura contemporânea do conceito de autonomia com base em conhecimentos construídos na biologia, filosofia, sociologia e na ética fica cada vez mais evidente que tanto a perspectiva da complexidade leva à autonomia, como a autonomia requer e leva à complexidade:

\footnotetext{
Quanto mais um sistema desenvolver sua complexidade, mais poderá desenvolver sua autonomia, mais dependências múltiplas terá. Nós mesmos construímos nossa autonomia psicológica, individual, pessoal, por meio das dependências que suportamos (...). Toda a vida autônoma é uma trama de incríveis dependências. (...) o conceito de autonomia não é substancial, mas relativo e relacional. (Morin, 1996, p.282)
}

\section{Por uma concepção complexa de autonomia}

O primeiro princípio constitutivo de uma concepção complexa da autonomia passa a ser sua característica relativa e relacional, inseparável da dependência. Seria preciso, portanto, superar uma idéia ou um objetivo de se chegar a uma autonomia absoluta. Pensando isto no processo saúde/ doença, significa defender não a autodeterminação do paciente pura e simples, mas, ao contrário, o fortalecimento das relações entre pacientes e 
profissionais da saúde, entre pacientes e seus familiares, porque essas redes de autonomia/ dependência passam a ser vistas como fundamentais para o cuidado e para a saúde. O que é preciso superar é a dimensão autoritária ou paternalista dessas relações e caminhar no sentido de possibilitar a expansão da autonomia à medida que (e na medida em que) avança o processo terapêutico. Quando adoecemos, queremos e precisamos do cuidado dos outros, seja pelo conhecimento especializado que um profissional tem a compartilhar, seja pelo af eto e apoio emocional que tanto os profissionais quanto os amigos e familiares podem trazer. Isto, em si, não diminui a autonomia de uma pessoa doente; ao contrário, pode até fortalecê-la. O que se deveria evitar, entretanto, é que essa relação se torne uma relação de dependência, de sujeição daquele que, em um determinado momento de vida, está mais fragilizado e dependente do outro. Desse modo, na relação médico-paciente (ou nas demais relações sociais), defender a autonomia não é propor a inversão na relação de hegemonia que se tem hoje, mas reconhecer que ambos os sujeitos devem ter espaço e voz no processo, com respeito às diferenças de valores, expectativas, demandas, objetivos entre eles. A relação é - e deve permanecer - heterogênea, diversa, plural, reconhecendo-se, porém, que o sujeito do processo terapêutico é a pessoa doente. As medicinas e as tecnologias médicas, assim como os médicos e demais profissionais, devem se colocar como meios, instrumentos que podem e devem ser utilizados pelos doentes no processo saúde/doença. Estes devem ser estimulados, portanto, a se tornar mais ativos, críticos, conscientes e responsáveis pelo processo saúde/doença, a ter maior empoderamento, como vem inclusive sendo defendido por diversos grupos ativistas do campo da saúde, notavelmente das ONGs atuando em defesa de portadores de HIV e doentes com aids.

Vale ressaltar que considerar o doente como responsável por sua doença não é, de forma alguma, concordar com o discurso que considera a doença uma punição e o doente um "fracassado", "culpado" por sua situação e que, portanto, pode ser estigmatizado, isolado socialmente. Não é, tampouco, responsabilizar o indivíduo para reduzir gastos governamentais com saúde, e/ ou para que o governo se libere de suas responsabilidades, como parece ser a direção muitas vezes tomada por políticas neoliberais.

É preciso rever o pressuposto básico da modernidade, o da existência de um indivíduo racional, pois trata-se de um mito. Não se pode falar de indivíduo como isolado do coletivo - tanto Morin quanto Elias (1994a, 1994b) mostram que há de se superar essa dicotomia e pensar em relações complexas, i.e., complementares e antagônicas entre individual e coletivo, um afetando e sendo afetado pelo outro, um produzindo e sendo produzido pelo outro. Tampouco se pode falar de indivíduos puramente racionais: somos Homo sapiens/demens como nos define Morin, conscientes mas, também, inconscientes, racionais e emocionais, objetivos e subjetivos. Sobre esse tema, em uma crítica da concepção iluminista do homem, do racionalismo onipotente e da modernidade de um modo geral, Plastino (1996) também denuncia - entre outras - a unilateralidade de suas concepções centrais sobre o homem e suas relações sociais.

Assim, ao pensar o paciente em sua relação com os profissionais de saúde, teremos de considerá-lo um ser único, individual, mas, também, como um 
membro da espécie humana, que não pode ser pensado fora da sociedade e da cultura à qual pertence. O mesmo se aplica aos profissionais. Uma vez em instituições de saúde, públicas ou privadas - como é a tendência crescente na atenção à saúde -, há que se considerar mais esse elemento na reflexão. Passam a ser, então, relações atravessadas pelos limites dados por essas organizações e, neste sentido, autores como Illich (1975) trazem contribuições importantes, ao discutirem o processo de contraprodutividade da medicina, que contribuiu para a paralisação das capacidades de autonomia do ser humano.

A autonomia, ainda que como um vir-a-ser, merece ser resgatada como uma condição de saúde e de cidadania, da própria vida, um valor fundamental, portanto, mas que não é nem pode ser absoluta. É relativa e relacional, como dito acima, e deve ser construída em um processo de produção contínua em uma rede de dependências que é bastante maleável e que necessariamente se vê reduzida no adoecimento. Mas ela deve estar sendo construída de modo continuado em sua inter-relação com a dependência no cotidiano da prática. Isto implica, também, a dificuldade em se pensar autonomia no campo da saúde sem ter autonomia no campo mais geral da política e da vida. As relações de autonomia/ dependência estão presentes durante toda a vida dos seres vivos, seja no nível dos indivíduos, seja no nível das sociedades, países e até do planeta. Assim, concordamos com Castoriadis (1986), quando a afirma como valor fundamental dentro de um projeto de sociedade democrática e responsável.

Em uma leitura atualizada da autonomia, afirmá-la como valor implica a busca da democratização das relações entre profissionais e pacientes, da democratização de saberes, do reconhecimento, respeito e valorização da multiplicidade, da diversidade e das singularidades, maior responsabilidade e participação dos cidadãos, resgate e valorização da subjetividade e, acima de tudo, de uma ética de solidariedade e responsabilidade. O que nos leva a perguntar,sobretudo em casos de países como o Brasil, como garantir uma minimalidade autonômica dos sujeitos em relação ao seu processo saúde/ doença? É possível falar de um paciente autônomo, livre e consciente de suas escolhas, quando os constrangimentos de ordem econômica e social são de tal ordem, de ignorância por falta de acesso à informação, numa relação altamente desequilibrada de poder/saber entre médico e paciente, como é o caso, por exemplo, da relação que se estabelece nas instituições públicas de saúde brasileiras hoje? Quais as condições mínimas que devem ser garantidas em termos de justiça social, de condições de vida, eqüidade, informação, saber, para podermos pressupor a existência da possibilidade de autonomia?

Nessa perspectiva, a informação, a democratização do saber e das relações de poder que são construídas entre profissionais e pacientes, entre Estado - por meio das instituições governamentais - e sociedade civil, as questões éticas aí implícitas e a questão de uma maior autonomia dos cidadãos em relação às suas escolhas e decisões passam a ser centrais. Porém, não há que se confundir autonomia com individualismo, nem a liberdade como uma idéia abstrata, descolada do contexto sociocultural e político. A possibilidade de que cada pessoa possa gerir sua própria vida passa pelo conhecimento e reconhecimento dos limites, das alternativas 
existentes, por uma perspectiva democrática e ética, o que implica respeito ao outro, respeito e valorização das subjetividades, saber es e valores, assim como pela impossibilidade de pensar o indivíduo como independente do coletivo. Ser humano autônomo é aquele que reconhece sua necessidade do outro em todos os planos - afetivo, intelectual, emocional.

Uma outra implicação da defesa da autonomia como valor fundamental em uma sociedade democrática e responsável refere-se à formulação de políticas. Estas não deveriam ser políticas rígidas, mas diretrizes mais gerais que explicitem seus pressupostos e objetivos, deixando ampla margem de flexibilidade para que se possam adaptar estratégias diversas de acordo com as realidades concretas que vão se apresentando. Mas para isso, é claro que há toda uma transformação imensa a ser feita na educação e cultura, uma "reforma do pensamento" (Morin, 1998) que supere a perspectiva disciplinar, o pensamento cartesiano e dicotomias, tais como macro/micro, específico/ geral, causa/ efeito, individual/coletivo, racional/irracional, objetivo/subjetivo, para propor a compreensão dos processos de construção do conhecimento e o estímulo da capacidade crítica; ou seja, a formação de cidadãos conscientes, responsáveis, informados, em condições de debater, questionar e escolher projetos e participar de sua implementação, que não se deixem submeter às tecnologias e instituições, mas que as utilizem como instrumentos para a ampliação da autonomia.

Um outro ponto importante que surge dessa reflexão sobre autonomia é a necessidade de uma transformação profunda na concepção de saúde/ doença, pois um segundo princípio constitutivo da autonomia na perspectiva da complexidade seria a sua emergência como uma exigência necessária para a saúde, compreendida em seu sentido mais amplo, saúde como vida, como potência auto-recuperadora do organismo humano vivo (Dâmaso, 1992), como capacidade de romper normas e instituir novas normas (Canguilhem, 1995). Essa compreensão implica o reconhecimento e a valorização da diversidade, da multiplicidade, da capacidade criativa dos seres vivos, de sua necessidade de inter-relações de autonomia/dependência como condição mesma de vida (Morin 1977, 1980, 1994, 1996). Não há vida sem autonomia. Esta é uma característica de todos os seres vivos, faz parte da compreensão do que seja o fenômeno da vida/morte. Portanto, a terapêutica deveria ter como objetivo atuar no sentido de estimular essa nossa capacidade de autonomia e de cura ou, pelo menos, de criar novas normas (Canguilhem, 1995), para que possa ser considerada, de fato, uma terapêutica pela saúde.

É preciso superar, então, a lógica que vem regendo a utilização de medicamentos na biomedicina, que vem da desconfiança da capacidade da natureza, da crença no poder do homem de controlar a natureza, característica do pensamento iluminista. Como já foi discutido, a famacoterapêutica é ainda desenvolvida dentro da perspectiva da racionalidade científica mecanicista, buscando principalmente estimular ou inibir funções bioquímicas ou fisiológicas no homem para aliviar ou eliminar sintomas ou para alterar favoravelmente o curso de uma doença. Até que ponto os medicamentos vêm sendo utilizados no sentido de estimular a capacidade própria dos seres humanos de se auto-recuperarem ou de instituírem novas normas de vida? 
Voltamos, assim, à importância do resgate da autonomia no processo terapêutico e, de modo mais amplo, na vida social, pois - vale repetir Castoriadis (1986) - a autonomia é o modo de ser do homem e, portanto, uma política da autonomia deve ser o fundamento da construção de uma outra forma de sociedade.

\section{À guisa de conclusão}

Buscamos desenvolver, neste artigo, uma série de reflexões e implicações de um novo modo de ver a autonomia do paciente no processo terapêutico. Apresentamos, a seguir, uma breve síntese, a fim de destacarmos uma série de propostas concretas para a atual política de saúde.

Vimos que a autonomia é o modo de ser do ser humano e, portanto, uma precondição para a saúde e para a cidadania. Sem essa perspectiva, uma política de saúde não pode ser considerada como tal. Assim, a busca da construção da autonomia do paciente no processo saúde/doença passa a ser fundamental. Ela deve ser construída em um processo de produção contínua, em sua inter-relação com a dependência, no cotidiano, mesmo quando limitada como na doença. Assim, sujeito autônomo é aquele que reconhece sua necessidade do outro em todos os planos.

Partindo desses pressupostos, são muitas as implicações para diversos níveis da política de saúde. Em relação ao processo terapêutico em si, destacamos:

- a necessidade de fortalecimento das relações entre pacientes e profissionais, entre pacientes e seus familiares, para além do autoritarismo ou paternalismo;

. o reconhecimento da heterogeneidade, da diversidade das relações, e do doente como o sujeito do processo terapêutico;

- o reconhecimento de que as medicinas e as tecnologias médicas, assim como os médicos e demais profissionais envolvidos são apenas meios no processo terapêutico;

- o estímulo ao empoderamento (empowerment) e a responsabilidade dos doentes, em uma ética de solidariedade, respeito e responsabilidade no processo;

- as relações e os saberes no campo da saúde devem ser democratizados;

. há que se resgatar e valorizar a subjetividade e a dimensão do cuidado na medicina;

- a necessidade de transformações profundas nos conceitos de saúde e doença que são, ainda, a base da biomedicina.

Colocando a política de medicamentos em foco, passamos a ver a necessidade urgente de uma terapêutica que estimule a capacidade criativa e curativa dos sujeitos doentes. Devemos ter diretrizes mais gerais e flexíveis, construídas de forma democrática, no lugar das políticas rígidas, fechadas e reducionistas atualmente em vigor. Não é admissível mais uma proposta de uso "racional" dos medicamentos, já que a racionalidade é apenas um dos elementos em jogo. Se não defendemos a tomada de decisões unicamente a cargo dos especialistas, tampouco devemos cair em propostas de autocuidado medicalizado. É urgente construir políticas e ações concretas no sentido do uso crítico e ativo dessas e das demais tecnologias por cidadãos autônomos. 
Entre as implicações mais gerais a partir dessa releitura do valor da autonomia, discutimos a necessidade de construção de condições para a expansão real da capacidade de autonomia no campo mais geral da política e da vida. Para isto, é fundamental a democratização de informações, saberes e das relações de poder, a construção de uma ética de solidariedade e responsabilidade, a necessidade de profundas transformações na educação e na cultura. Vemos, portanto, que há um caminho árduo e bastante longo, mas absolutamente necessário para o avanço da saúde, em seu valor mais pleno e concreto.

\section{Referências}

BERLINGUER, G. A doença. São Paulo: Hucitec-Cebes, 1988.

BIRMAN, J. Os sentidos da saúde. Physis, v.9, n.1, p.7-12, 1999.

BLANC, G. Canguilhem et les normes. Paris: PUF, 1998.

BRODY, H. Autonomy revisited: progress in medical ethics: discussion paper. J. R. Soc. Med., n.78, p.380-7, 1985.

CANGUILHEM, G. O normal e o patológico. 4.ed. Rio de Janeiro: Forense Universitária, 1995.

CAPONI, S. Georges Canguilhem y el estatuto epistemológico del concepto de salud. Hist. Ciênc. Saúde Manguinhos, v.4, n.2, p.287-307, 1997.

CASTORIADIS, C. A instituição imaginária da sociedade. 2.ed. Rio de Janeiro: Paz e Terra, 1986.

CLAVREUL, J. A ordem médica: poder e impotência do discurso médico. São Paulo: Brasiliense, 1983.

COELHO, M.T.A.D.; ALMEIDA FILHO, N. Normal-patológico, saúde-doença: revisitando Canguilhem. Physis, v.9, n.1, p.13-36, 1999.

. Conceitos de saúde em discursos contemporâneos de referência científica. Hist. Cienc. Saúde Manguinhos, v.9, n.2, p.315-33, 2002.

DÂMASO, R. Saúde e autonomia: para uma política da vida. In: FLEURY, S. (Org.). Saúde: Coletiva? Questionando a onipotência do social. Rio de Janeiro: Relume-Dumará, 1992. p.213-31.

ELIAS, N. El proceso de la civilización: investigaciones sociogenéticas y psicogenéticas. México: Fondo de Cultura Económica, 1994a.

A sociedade dos indivíduos. Rio de Janeiro: Jorge Zahar, 1994b.

FOUCAULT, M. La crisis de la medicina o la crisis de la antimedicina. Educ. Med. Salud, v.10, n.2, p.152-70, 1976.

O nascimento da clínica. 2.ed. Rio de Janeiro: Forense Universitária, 1980.

ILLICH, I. A expropriação da saúde: nêmesis da medicina. Rio de Janeiro: Nova Fronteira, 1975.

JONAS, H. Técnica e responsabilidade: reflexões sobre as novas tarefas da Ética. In: Ética, medicina e técnica. Lisboa: Veja, 1994. p.27-61.

LAINE, C.; DAVIDOFF, F. Patient-centered medicine. A professional evolution. JAMA, n.275, p.152-6, 1996.

LUZ, M.T. V Seminário do Projeto Racionalidades Médicas. Rio de Janeiro: UERJ, IMS, 1996. (Estudos em Saúde Coletiva, 136) 
SOARES, J.C.R.S.; CAMARGO JUNIOR, K.R.

MORIN, E. La méthode. La Nature de la Nature. Paris: Éd. du Seuil, 1977. v.1.

La méthode. La Vie de la Vie. Paris: Éd. du Seuil, 1980. v.2.

La complexité humaine. Paris: Flammarion, 1994.

Ciência com consciência. Rio de Janeiro: Bertrand Brasil, 1996.

. La democratie cognitive et la reforme de la pensée. In: I CONGRESSO INTER-LATINO DO

PENSAMENTO COMPLEXO - Cilpec, 1., 1998, Rio de Janeiro. Anais... Rio de Janeiro: Universidade

Cândido Mendes, Association pour la Pensée Complexe, 1998. (Mimeogr.)

PINHEIRO, R.; MATTOS, R.A. (Orgs.). Os sentidos da integralidade na atenção e no cuidado à saúde. Rio de Janeiro: UERJ/IMS/ABRASCO, 2001.

PLASTINO, C.A. Os horizontes de Prometeu: considerações para uma crítica da modernidade. Rio de Janeiro: UERJ/IMS, 1996. (Estudos em Saúde Coletiva, 141)

QUILL, T.E. Partnerships in patient care: a contractual approach. Ann. Intern. Med., n.98, p.228-34, 1983.

QUILL, T.E.; BRODY, H. Physician recommendations and patient autonomy: finding a balance between physician power and patient choice. Ann. Intern. Med., n.125, p.763-9, 1996.

QUILL, T.E.; SUCHMAN, A.L. Uncertainty and control: learning to live with medicine's limitations. Hum. Med., n.9, p.109-20, 1993.

SOARES, J.C.R.S. A autonomia do paciente e o processo terapêutico: uma tecedura complexa. 2000. 180p. Tese (Doutorado) - Instituto de Medicina Social, Universidade Estadual do Rio de Janeiro, Rio de Janeiro.

SWAAN, A. Conclusion: the collectivizing process and its consequences. In: . In care of the State: health care, education and welfare in Europe and the USA in the Modern Era. Cambridge: Polity Press, 1988. p.218-57.

VIEIRA, M.C.A. O desafio da grande saúde em Nietzsche. Rio de Janeiro: Sete Letras, 2000.

SOARES, J.C.R.S.; CAMARGO JUNIOR, K.R. Autonomía del paciente en el proceso terapéutico como valor para la salud. Interface - Comunic., Saúde, Educ., v.11, n.21, p.65-78, jan/abr 2007.

En este trabajo se analizan las críticas a las concepciones reduccionistas de salud y enfermedad, procurando contribuir para el repensar sobre la salud en una vertiente de propuestas positivas. Nos concentramos, principalmente, en la epistemología de Canguilhem para destacar puntos fundamentales en la discusión sobre la salud, integrándola a una nueva lectura del concepto de autonomía del paciente en el proceso terapéutico. El método de análisis siguió la perspectiva del pensamiento complejo. En esta perspectiva, la autonomía se caracteriza como relacional y relativa, inseparable de la dependencia. Es también una condición necesaria para la salud, comprendida en su sentido más amplio, como una potencia auto-recuperadora del organismo humano. Así, la autonomía pasa a ser un valor fundamental que debe ser recuperado y defendido, tanto en la clínica como en el campo de las ciencias humanas y sociales en salud. Se discuten las consecuencias de rescatar la autonomía, aunque sea como un "venir-a-ser", como una precondición para la salud y la ciudadanía, y para la propia vida.

PALABRAS CLAVE: relacion médico-paciente. autonomia del paciente. saúde. Canguilhem. pensamiento complejo.

Recebido em 08/11/05. Aprovado em 20/09/06.

78 Inteface- Comunic, Saúde, Educ, v.11, n.21, p.65-78, jan/abr 2007 